\title{
A Qualitative Study on the Influence of Quality Systems in Meeting Performance Funding Criteria in Wisconsin Technical College System Institutions
}

\author{
Kinga N. Jacobson \\ University of Wisconsin-Stout
}

\begin{abstract}
This case study investigated the influence of quality systems on meeting performance funding criteria in Wisconsin Technical College System institutions. Using qualitative text-analysis methodology, the case study identified the common processes, systems, values, and culture of three Wisconsin Forward Award-recognized technical colleges, looking for ways these characteristics were used for attaining performance-based funding goals. Sources analyzed included the colleges' Wisconsin Forward Award application documents and evaluator feedback reports, and the transcripts of six interviews conducted with professionals with expertise in organizational effectiveness and performance funding at these institutions. Findings indicated that the entities shared quality, benchmarking, feedback, strategic planning, and budgeting processes and systems, as well as student-focused values and culture. The case study conclusions suggested that these commonalities were not aligned with performance-based funding goals. Interviewees felt that it was too early to draw conclusions on the effectiveness of these goals. The researcher recommends consideration of the processes, systems, values, and culture shared by these colleges by other technical colleges, and improved alignment of organizational practices with performance-based funding expectations. Suggestions also include improving the convergence of various state accountability and quality improvement initiatives to reduce leading institutions in divergent directions.
\end{abstract}

Keywords: Malcolm Baldrige Performance Excellence, higher education accreditation, quality improvement in higher education, performance-based funding, higher education accountability

\section{Introduction}

In the past few decades, the United States higher education system, known for diverse and flexible programming, has been criticized for lacking accountability. Critics cited its focus on access rather than student success, inadequate student learning outcomes, and limited transparency and efficiency. Low retention and graduation rates, admission of underprepared learners, insufficient support for struggling students, noncompetitive graduates in the global workplace, and misalignment of higher educational strategies and public priorities have been used to support these claims. Experts called upon postsecondary leaders to "increase quality, effectiveness, and efficiency in response to internal and external pressures” (Ruben, 2007, p. 3), encouraging assessment of organizational success in light of student achievement.

Authorities responded by making educational accountability the epicenter of the 1998 Higher Education Act reauthorization. Traditionally, accreditation involved authorization or reaffirmation of higher education institutions based on mission, programs, enrollment, and faculty scholarship, without specific concern for student learning outcomes or operational effectiveness; it was a once in a decade event evaluating past performance rather than a continuous improvement endeavor (Shakir, 2010). Accountability initiatives transformed expectations, making constant quality improvement and results the new norm in higher education accreditation.

However, student learning outcomes assessment, at the heart of public attention and accreditation (Duque \& Weeks, 2010), was not uniform, rendering unreliable comparisons across institutions (Middaugh, 2012). Data inconsistencies and inadequate quality management (Mehralizadeh \& Safaeemoghaddam, 2010) resulted in the introduction of outcome-focused funding models.

Proposed as a solution for augmenting operational effectiveness and achievement, performance-based funding intended to reduce the gap between the goals of public postsecondary institutions and state priorities. Target goals included increased degree attainment, support for state workforce needs, and economic 
progress, shifting funding from inputs to outputs and "tying state appropriations to institutional performance on measures such as retention, graduation rates, and degrees conferred” (McCready, 2013, p. 1).

The Wisconsin performance-based funding model was introduced in 2013 as a state budget method connecting taxpayer investment and Wisconsin Technical College System performance. Designed to enhance transparency and promote accountability, appropriations were based on the categorical outcomes of the previous three fiscal years. Measured were: the number of industry-validated degrees and certificates in high-demand fields; service to adults in basic education and remedial courses; student placement in program of study related jobs; participation in dual enrollment plans, workforce training, and statewide initiatives; and service to special populations and demographic groups (Wisconsin Technical College System, 2015).

Governed by Chapter 38 of the Wisconsin Statues and the Wisconsin Technical College System Board, the sixteen technical colleges feature similar missions, structure, and operational policies, but differ in size, strategic leadership, and populations served. Over time, they demonstrated varying degrees of interest in quality frameworks, some focusing strictly on accreditation requirements while others also pursuing optional quality improvement alternatives, such as the Wisconsin Forward Award.

The Wisconsin Forward Award, a streamlined and reduced-cost version of the national Malcolm Baldrige Performance Excellence Award, was established in 1997. Since, fourteen Wisconsin Technical College System schools have been acknowledged at one of the four recognition levels (American Society for Quality, 2015). While commitment to a culture of excellence is commendable, consumption of scarce organizational resources to pursue Wisconsin Forward Award recognition was value-added only if it improved the colleges' preparedness to meet state performance criteria (Hanushek \& Lindseth, 2009).

If Wisconsin Forward Award applicants benefitted from embedding these quality standards into their operations by positioning themselves favorably in the performance-based funding environment, then their effort was worthwhile. If, however, the exercise did not assist colleges in developing state performance criteriaaligned organizational efficiencies, then participating in this optional quality initiative could be wasted organizational effort; these colleges would have benefited more from alternative performanceimprovement options than the Wisconsin Forward Award framework (Hillman, Tandberg, \& Fryar, 2014).

\section{Purpose of Study}

The problem statement proposed was the lack of evidence that satisfaction of the Wisconsin Forward Award standards enhanced a technical college's ability to meet performance-based funding goals through development and use of effective organizational processes, systems, values, and culture. There was no proof that recognition of technical colleges by the Wisconsin Forward Award translated into success in attaining performance-based funding.

The goal of this study was to identify organizational characteristics shared by Wisconsin Forward Awardrecognized Wisconsin Technical College System institutions and to explore these characteristics in the context of performance-based funding. In other words, the study explored whether three specific Wisconsin Forward Award-recognized technical colleges displayed common processes, systems, values, or culture and whether these organizational features were utilized in meeting performance-based funding criteria.

This qualitative case study sought answers to the following two research questions:

1. What common organizational processes, systems, values, and culture do the Wisconsin Forward Award-recognized technical colleges display? Namely, do these colleges feature key characteristics that could benefit their peers if implemented in their organizational strategy and operations?

2. How do the Wisconsin Forward Awardrecognized technical colleges use their processes, systems, values, and culture to meet performance-based funding targets? Specifically, do their common organizational characteristics translate into effective practices and strategies for attaining performance criteria goals?

\section{Literature Review}

Accreditation and Quality Improvement in Higher Education. Demands for heightened accountability increased the role of accreditation in higher education, being considered "the only organized means by which the academe provides quality assurance to the general public" (Wergin, 2005, p. 35). Accreditation agencies across the nation aligned their mission with promotion of an internal culture of evidence where "data collected informs institutional decisionmaking, planning, and improvement" (Western Association of Schools and Colleges, 2002, p. 6).

Historically, accreditation focused on mission, programs, and faculty expertise without consideration for student learning outcomes or financial accountability. Much like the traditional higher education funding formula, it was input, rather than output driven. Today, accreditation involves evaluation of the institution's standing relative to four assumed practices and five accreditation criteria including mission-orientation, ethical conduct and responsible use of financial resources, teaching and learning quality and assessment, and strategic planning and institutional effectiveness (Higher Learning Commission, 2016). 
Despite efforts to improve college and university results through accreditation, quality was difficult to define with simplistic indicators. Experts proposed that traditional productivity tools might not be well fitted for complex postsecondary teaching and learning because "the inputs and outputs in the production process are difficult to define and quantify" (Sullivan, Mackie, Massy, \& Sinha, 2012, p. 1). Zhang's research (2009) on student learning outcome quality in accredited institutions found considerable variation across the United States, and a study on secondary quality efforts indicated wide and persistent disparities across schools (Shields \& Mohan, 2008).

The body of knowledge suggested that effective communication of expectations was essential for quality control (Smith, 2011), underscoring the importance of leadership in engraining a culture of quality across an organization. Burke (2002) spoke to the significant role of administrators in the success or failure of new initiatives, including driving change, generating wide scale acceptance, developing performance goals-based strategic plans, and instilling commitment to results. Visionary leaders helped employees embrace new initiatives and achieve new levels of performance (Bass, Avolio, Jung, \& Berson, 2003) because of their "high job satisfaction level and greater commitment to change implementation” (Hinduan, Wilson-Evered, Moss, \& Scanell, 2009, p. 59).

In 1999, the Higher Learning Commission, the accrediting body for the three institutions in this study, underwent a major mission overhaul to "increase the focus of accreditation on the quality of higher learning, and provide multiple processes with emphasis on the institution's own processes of quality assurance and quality improvement” (Crow \& Van Kollenburg, 2003, p. 4). Currently, the three options for gaining or reaffirming accreditation are the Program to Evaluate and Advance Quality Standard Pathway, the Academic Quality Improvement Program, and the Open Pathway. Hamilton and Black (2001) asserted accrediting bodies' interest in a range of new approaches, as "no single accreditation process represents the only, or best way to assure and advance quality” (Crow \& Van Kollenburg, 2003, p. 5).

The changes affected Wisconsin Technical College System institutions; some remained true to the traditional, while others progressed to newer accreditation models. Upon the rollout of the new Higher Learning Commission accrediting options, Chippewa Valley Technical College, Western Technical College, and Milwaukee Area Technical College elected to move from the traditional plan to the new Academic Quality Improvement Program, demonstrating an interest in quality improvement-based performance early on.

The new Academic Quality Improvement Program shifted the focus "from a model of compliance to one of continuous improvement” (Shakir, 2010, p. 2). It was designed to address the weaknesses of the traditional accreditation plan, reflect best practices suitable for higher education, and propose an organizational change process fitted for the needs of higher education. Spangehl (2004) indicated that the model customized the underlying quality principles to the needs of higher education, applying tools that worked well in other arenas to education, while respecting its traditions. It helped leaders think through the role of the culture of evidence, and make better decisions using good information (Spangehl, 2004). These outcomes informed the current study, suggesting that quality systems could be effective means of improving the performance of postsecondary schools.

Malcolm Baldrige Performance Excellence in Higher Education. The Malcolm Baldrige Performance Excellence framework is a globally recognized improvement system that proposes seven categories for evaluating institutional processes and performance (National Institute of Standards and Technology, 2015). The indicators represent fundamental drivers of high performing, leading-edge organizations. The Malcolm Baldrige Performance Excellence program provided context for the analysis of processes, systems, values, and culture shared by the three colleges researched because the Wisconsin Forward Award and the Academic Quality Improvement Program are based on these standards.

The Malcolm Baldrige Performance Excellence Award, originally called the Malcolm Baldrige National Quality Award, was established "to raise awareness of quality and recognize national role models" (Evans, 2014, p. 12). By way of this award, national recognition is given to companies focused on productivity improvement and excellent results in order to "guide others through example in their quest to manage for high quality" (Evans, 2014, p. 61). The program's benefits were shown by studies revealing an 820 to 1 benefit-tocost ratio for the United States economy (Evans, 2014).

Effectiveness resulted in widespread popularity, the program becoming one of the most prestigious recognitions in the United States. The framework, originally designed for business and industry, was later adapted to the needs of service, education, and health care organizations, and even for nonprofits. These aspects substantiate examination of the standards in support of this study involving processes, systems, values, and culture in Wisconsin Technical College System institutions operating in a performance-funding context.

Wisconsin Forward Award in the Wisconsin Technical College System. The complexity and cost of the Malcolm Baldrige Performance Excellence Award deterred many smaller, regional entities from applying. To counteract these shortcomings, many states established recognition programs featuring similar standards and objectives, but streamlined application logistics and reduced cost.

Wisconsin Governor Tommy Thompson established the Wisconsin Forward Award in 1997. It was modeled after the national Malcolm Baldrige Performance 
Excellence Award, but limited to institutions operating within the State of Wisconsin. Through this platform Wisconsin distinguished companies and institutions that "enable themselves to be successful and innovative, keeping Wisconsin in a State of Excellence" (Wisconsin Center for Performance Excellence, 2015, para. 2). The seven Wisconsin Forward Award standards, similar to the national Malcolm Baldrige Performance Excellence program, were grouped into seven categories including leadership; strategic planning; student, stakeholder and market focus; measurement, analysis, and knowledge management; workforce focus; process management; and results (Moss-Kanter \& Page, 2011). Together, these standards presented a system for measuring and recognizing four levels of progress and growth toward performance excellence through a systematic assessment process (Wisconsin Center for Performance Excellence, 2015).

The four award levels, namely commitment, proficiency, mastery, and excellence represent developmental stages in an entity's pursuit toward reaching the highest level of performance quality. Excellence, the highest award level, signifies entities that "consistently demonstrate management excellence through quality practices and superior achievements, being outstanding quality enterprises that serve as role models for others" (Wisconsin Center for Performance Excellence, 2015). These institutions advanced full circle from assessing themselves against industry benchmarks, learning their strengths and weaknesses, incorporating innovative approaches that produce exceptional results, to becoming sought-after benchmarks in their field (Evans, 2014).

Chippewa Valley Technical College, Western Technical College, and Milwaukee Area Technical College, the three institutions examined in this study, embarked on the Wisconsin Forward Award quality journey, considering the framework a feasible option for enhancing operational effectiveness and achieving statelevel distinction. Essential sources for this qualitative study were the Wisconsin Forward Award application submissions and the corresponding feedback reports used to investigate the colleges' common processes, systems, values, and culture, and whether these characteristics were engaged in meeting performance-funding goals. By choosing to measure up to the rigorous quality criteria set forth by the Wisconsin Forward Award, these colleges became postsecondary education performance excellence pioneers. Later on, they confirmed their continued commitment to quality by readily embracing the Academic Quality Improvement Program accreditation pathway introduced by the Higher Learning Commission.

Performance-Based Funding. Traditionally, United States higher education was funded with an enrollment/cost-based approach reliant upon forecasts of expenses relative to number of students enrolled, current operating costs plus annual increases, add-ons for new program development, student support services, administrative expenses, and building maintenance and expansions, among others (SRI International, 2012). This model worked with budgetary functional areas and a base plus/minus method or legislative mandates to determine the amount of funds received by each institution. According to Dougherty and Natow (2015), this approach "relies on a combination of enrollment numbers and prior-year funding level, giving colleges and universities little incentive to focus on retaining and graduating students or meeting state needs" (p. 2).

As policymakers looked for ways to align higher educational goals with state priorities, they wanted increased degree attainment, support for the states' workforce needs, and economic progress (Blanco, 2012). The traditional enrollment-based funding created a gap between the goals of postsecondary institutions and the state (Hillman, Kelchen, \& Goldrick-Rab, 2013). When the goal was improvement of graduation rates, then the enrollment-based formula was not suitable due to its association with low degree completion (SRI International, 2012).

Pressures for higher accountability and better student learning outcomes shifted attention from enrollment-based to results-driven funding models (Burke, 2002). Experts stated that higher education needed to accomplish the improvements while reducing tuition and fees through increasingly lean operations and increased productivity, underscoring the role of transformational leaders (Hammer \& Champy, 1993). These findings were instrumental in providing context for the present research involving technical colleges subject to state-mandated performance excellence criteria.

National and state policymakers stepped up, advancing performance funding as a new higher educational quality assessment model. Christal (1998) indicated "in state after state, legislators have directed government entities, including public higher education, to state their goals and activities more explicitly, and report results as a form of accountability” (p. vii). This meant that colleges and universities identified student learning outcome targets to be met by programs, developed indicators to measure results, and relied on assessment data for performance improvement (Burke, 2002).

Despite the progress made, resistance to external accountability was still strong within institutions. Williams (2005) indicated, "literature supports the fact that a gap clearly exists between the national acceptance of assessment activities and its limited impact on individual campuses” (p. 28). Burke (2002) acknowledged that campuses shunned the notion of accountability, and that great variation existed among institutions on what to measure, and how to implement a measurement system capable of rendering reliable results.

Ultimately, performance reporting and evidence won the debate and external accountability became the norm across higher education (Burke, 2002). States implemented performance-reporting requirements on 
accessibility, efficiency, productivity, and quality standards for public postsecondary schools. A results focus and advancement of state priorities in addition to internal process improvement was now expected of publicly funded higher education institutions.

Performance funding was the natural next step in policymakers' quest to improve accountability in higher education. This model was shown to augment the prominence of improved organizational effectiveness and achievement as two- and four-year public colleges competed for limited state funding (McCready, 2013). According to McCready (2013) "performance funding represents a shift from input-driven to output-driven funding, tying state appropriations to institutional performance on measures such as retention, graduation rates, and degrees conferred” (p. 1). Though opinions were divergent on the benefits versus challenges of this funding formula, supporters felt that while the "inputbased funding used in the past provided stability and fiscal certainty for Wisconsin educational institutions, it also created a potentially perverse incentive to focus on enrolling students rather than graduating them” (Hillman, Kelchen, \& Goldrick-Rab, 2013, p. 1).

Key to a winning model was alignment with state priorities. If access to higher education and increased participation were the goal, especially in states with high percentages of underserved and low-income populations, then enrollment-based funding was suitable. However, "it is serious waste of public resources to admit students to college who then drop out without a qualification" (SRI International, 2012, p. 11) so "states needed to devise policies promoting completion and efficiency across their higher education systems” (Heineman \& Daniels, 2015, p. 3). The literature review found that when states struggled with low graduation and completion rates, policymakers often incentivized student success outcome improvement through performance funding. This explained why Wisconsin policymakers chose this model for funding Wisconsin Technical College System institutions.

Organizations subjected to performance funding standards were required to meet specific criteria for budget allocations (Hall \& Kalk-Derby, 2012). The amount of funds received by two-year postsecondary schools was dependent on attainment of expected outcomes (Miao, 2012). Consequently, institutions needed to align their operations with the proposed standards, allocating use of their limited resources with state goals. Performance funding was to close the gap created by the traditional enrollment-based approach, facilitating student graduation, and aligning institutional mission with state needs (Reindl \& Reyna, 2011), all highly desired goals in Wisconsin Technical College System colleges struggling with low graduation, retention, and credentialing statistics.

Burke and Modarresi (2000) rationalized that assessment-driven accountability practices, even though popular among external stakeholders, legislators and the public, were not well received by internal stakeholders such as faculty and administrators. The differing perception, termed a "tension" between external and internal accountability across the existing knowledge base (Noland \& Davis, 2000), led to several performancebased funding policy iterations aiming to bring the two sides closer to an agreement. Adoption fluctuated over time, but a nationwide analysis found that 26 states implemented some performance-based funding model between 1997 and 2007 (HCM Strategists, 2011). As of now, approximately $63 \%$ of the fifty states have embraced this model for financing higher education in hopes of improved student success outcomes and better alignment with state needs.

The experience of the early performance-based funding implementers was mixed; some enjoying lasting success while others having to cut programs due to lack of alignment with state goals, public pushback, undue design complexity, lack of data, or reduced fund pools (SRI International, 2012). Even in states where the model persisted for years, it had undergone considerable change. Recent research reported that in states that no longer use this model the discontinuation was primarily due to "erosion of political support" (Dougherty \& Natow, 2015, p. 10) not ineffectiveness. Further, design and implementation challenges, including lack of institutional capacity, equity, and opposing views were commonly cited as obstacles to long-term success (HCM Strategists, 2011).

Wisconsin Governor Scott Walker introduced performance-based funding in 2013 as a state budget method establishing a direct connection between taxpayer investment and Wisconsin Technical College System performance (Wisconsin Technical College System, 2015). Wisconsin Technical College System leaders explained that under this formula the colleges were to be measured on seven out of nine criteria to chart progress, enhance transparency, and promote accountability. Colleges' appropriations were to be calculated based on their performance score in each category, using data from the previous three fiscal years (Wisconsin Technical College System, 2015). As the amount of funding received by each school was dependent on attainment of expected outcomes (Miao, 2012), institutions were to align their operations with the prescribed standards, prioritizing their resource-use in light of these expectations.

This literature review provided the contextual knowledge necessary for assessing the findings of this qualitative analysis investigating the processes, systems, values, and culture shared by Chippewa Valley Technical College, Western Technical College, and Milwaukee Area Technical College, as well as the use of these features in reaching performance-funding targets.

\section{Methodology}

This study utilized qualitative case study methodology suited to analyze and report on specific situations with insight difficult to discern from 
quantitative reports. The case study, a type of ethnographic research that describes, analyzes, and interprets shared characteristics and patterns of behavior of individuals or groups over time, uses broad, general questions and collects detailed evidence through observation and participant interviews (Lichtman, 2013); it relies on interpretive design to reach its conclusions, connecting data, study questions, and deductions (Yin, 1994).

The qualitative methodology, an "inquiry approach useful for exploring and understanding a central phenomenon" (Creswell, 2012, p. 626) facilitates examination of sensitive, complex, or difficult topics, enabling identification of previously unobserved connections (Griffin, 2002). It supports the goals of the study by lending flexibility in data interpretation and a non-restrictive presentation format (Creswell, 2012).

Subject Selection. This case study involved the information rich-cases of Chippewa Valley Technical College, Western Technical College, and Milwaukee Area Technical College, purposefully sampled for their involvement with the Wisconsin Forward Award and performance funding. Of the sixteen Wisconsin Technical College System schools, these three institutions were recognized with the Wisconsin Forward Award within the past five years, a key criterion for selection. The multi-case approach allowed insights and comparisons impossible with a single case (Stake, 1995), rendering more convincing and generalizable findings (Fraenkel, Wallen, \& Hyun, 2012).

Chippewa Valley Technical College serves the substantially rural, developing Western edge of Wisconsin; Western Technical College, the smallest of the three, positions itself as the college of first choice for credit and non-credit courses in its Western Wisconsin region; Milwaukee Area Technical College, the largest of the three colleges, serves the greater Milwaukee metropolitan area with comprehensive services.

Instrumentation. Source materials included the Wisconsin Forward Award application packages and evaluator feedback reports of Chippewa Valley Technical College, Western Technical College, and Milwaukee Area Technical College, and transcripts of the semistructured interviews conducted with study participants. Interview participants were chosen explicitly for their expertise and experience with organizational effectiveness and performance reporting at each technical college. The individuals fit the criteria of understanding in depth the processes, systems, values, and culture of their institutions, being "expert informants yielding the best understanding of what is being studied" (Fraenkel, Wallen, \& Hyun, 2012, p. 436); specifically, the six interviewees included two executives and/or financial performance professionals from each college.

The interview questionnaire contained four openended questions asking participants to share their experience with processes, systems, values, and culture at their institutions and to identify how these were used for meeting performance-based funding criteria. The questions were formulated in alignment with professional literature and expert adviser recommendations to support the research goals. The 20-40 minute semi-structured phone interviews were recorded, and then transcribed in preparation for text-analysis. The interview questions were:

- What organizational processes and systems does your institution use?

- What are the values and culture of your organization?

- How are these characteristics used to meet performance-based funding targets?

- $\quad$ Are these strategies and practices effective in securing performance-funds?

Data Analysis. The source documents were analyzed using NVivo qualitative research analysis software. The main data analysis method was textanalysis, a typical "systematic procedure for reviewing or evaluating documents” (Bowen, 2009, p. 27) and an interpretation of text to form meaning (Corbin \& Strauss, 2008). The approach suited the task of coding complex source documents, including semi-structured interview responses, because research question specific answers could be discerned non-obstructively, economically, and relatively simply through analysis of written communications, without being limited by time or location (Fraenkel, Wallen, \& Hyun, 2012). Coding recurring themes and patterns in the Wisconsin Forward Award applications and feedback reports rendered a list of common organizational characteristics, representing processes, systems, values, and culture shared by the three technical colleges examined (Table 1). Coding the interview transcripts resulted in a list of shared features as well as insights relative to the usage and effectiveness of these features in attaining performance-based funding (Table 2).

Limitations of the Study. The research was limited to the specific cases of Chippewa Valley Technical College, Western Technical College, and Milwaukee Area Technical College, rather than evaluating all Wisconsin Technical Colleges distinguished with the Wisconsin Forward Award over the years. A main criterion for inclusion in the study was Wisconsin Forward Award recognition within the past five years. Additional limitations were the changing configuration of the Wisconsin performance-based funding framework and the restricted applicability of findings to secondary education and postsecondary schools outside the state.

Qualitative research, while a fitting choice for the purposes of this study, can render inconsistencies and contradictions within and between individuals' accounts (Burman \& Parker, 1993). The subjective aspects of any qualitative investigation, including sample selection, document coding and analysis, assumptions made, and conclusions drawn affect the extent in which a repeat 
study can result in the exact same conclusions. Researcher bias, such as views on higher education funding, professional experience, and partiality involving the status and relationship of the researcher and respondents can limit the impact of qualitative studies by the results being discounted (Reyes \& Halcon, 1988).

\section{Findings}

Processes and Systems. The most often referenced themes in the Wisconsin Forward Award documents (Table 1) highlight five major process and systems groups shared among the three colleges: quality, benchmarking, feedback, strategic planning, and societal responsibility.

Quality. Quality processes and systems included the Academic Quality Improvement Program, the Plan Do Check Act method, the Higher Learning Commission accreditation activities, the Quality Review Program, and budgeting. Specifically, Chippewa Valley Technical College's application (2012) stated, "the college uses the Academic Quality Improvement Program to ensure compliance in its accreditation process" (p. xxvii); Western Technical College's performance improvement system consists of "college and program scorecards, comprehensive evaluation of instructional programs through the Quality Review Process, and cross-functional teams that address organizational and student performance issues using the Plan Do Check Act method" (Western Technical College, 2011, p. xv);
Milwaukee Area Technical College was "committed to continuous improvement processes using a Plan Do Check Act learning cycle and other relevant data” (Milwaukee Area Technical College, 2012, p. v).

Benchmarking. Benchmarking involved Wisconsin Technical College System and competitor comparisons, Integrated Postsecondary Education Data System reports, and National Community College Benchmarking Project topics. Milwaukee Area Technical College (2012) documents explained, “a Strengths, Weaknesses, Opportunities, and Threats analysis conducted in 2011 revealed strategic advantages, including MATC's competitive cost” (p. v). Western (2011) benchmarked "against fifteen other postsecondary institutions in Wisconsin with similar missions, visions, values, organizational structures, policies, student demographics, and resources" (p. xiv).

Strategic planning. Strategic planning involved mission and vision, core values, and core competencies. Western Technical College (2011) noted, "strategic planning propels the organization towards its vision of college of first choice in the region” (p. 7); Chippewa Valley Technical College (2012) had "a comprehensive, collaborative strategic planning process that addresses strategic challenges, shapes annual operations, and informs the future” (p. 6).

Feedback. Feedback processes and systems comprised the Personal Assessment of College Environment, the Student Satisfaction Inventory, and the Community College Student Success Engagement surveys, as well as advisory committees and partnership

Table 1. Thematic Node Ranking Based on Aggregated Number of References

\begin{tabular}{clc}
\hline Ranking & Thematic Node & \# of References \\
\hline 1 & Processes \& Systems & 681 \\
2 & Measurement & 427 \\
3 & Strategic Planning & 255 \\
4 & Student Focus & 190 \\
5 & Benchmarking & 159 \\
6 & Feedback & 140 \\
7 & WTCS & 121 \\
8 & Mission \& Vision & 104 \\
9 & Societal Responsibility & 95 \\
10 & Core Values & 93 \\
11 & PACE & 84 \\
12 & Budgeting & 73 \\
13 & AQIP & 56 \\
14 & PDCA & 55 \\
15 & SSI & 51 \\
16 & Competitors & 51 \\
17 & Partnerships & 49 \\
19 & QRP & 42 \\
20 & Advisory Committees & 39 \\
21 & HLC & 30 \\
23 & CCSSE & 30 \\
& IPEDS & 29
\end{tabular}


listening sessions. Western Technical College (2011) stated, "participation in the Higher Learning Commission's Academic Quality Improvement Program, Baldrige Performance Excellence Program, and the Continuous Quality Improvement Network provides an opportunity for the college to receive feedback from peers and individuals outside education" (p. 4); Milwaukee Area Technical College (2012) indicated that stakeholders provided input through "focus groups, cross-functional teams, District Board meetings, MATC Days, town hall meetings, advisory committees, student follow-up surveys” (p. 21).

Societal responsibility. The broad societal responsibility category encompassed diversity, equity, safety, emergency preparedness, sustainability, and financial accountability processes and systems.

The interview findings supported the inferences made based on the Wisconsin Forward Award sources. Participant responses confirmed that the process and systems common to the three institutions researched based on the outcomes of the Wisconsin Forward Award document analysis remained dynamic organizational features despite the context altered by performance funding legislation. Three or more interviewees itemized the Academic Quality Improvement Process used by Higher Learning Commission accreditation, the Quality Review Process applied in the Wisconsin Technical College System, the Plan Do Check Act method, and budgeting (Table 2).

Interviewee testimonials reinforced the discoveries, suggesting, "Western is part of a network called Continuous Quality Improvement Network involving primarily colleges and universities; is very beneficial to utilize for various issues, including quality issues, and best practices” (C. S., personal communication, 2016). A Chippewa Valley Technical College respondent specified, "We have feedback that comes through the Higher Learning Commission; we are an Academic Quality Improvement Program college” (A.S., personal communication, 2016).

Values and Culture. After establishing processes and systems common to Chippewa Valley Technical College, Western Technical College, and Milwaukee Area Technical College, the investigation turned to culture aspects. Mission and vision, values, and core competencies were evaluated in light of their role in supporting student success.

Mission, vision, and values: According to the Wisconsin Forward Award source documents the three institutions shared a student-focused organizational culture. Student centeredness at Milwaukee Area Technical College was demonstrated by pursuing a vision of "enriching, empowering, and transforming lives in the community” (Milwaukee Area Technical College, 2012, p. 13). Western Technical College's mission (2011) suggested, "Western Technical College provides relevant, high quality education, in a collaborative and sustainable environment that changes the lives of students and grows our communities” (p. xi). Interview transcripts showed a strong commitment to culture as driver of organizational mission and performance. Western Technical College had "a value statement we stand by; we value the success of our students and hold ourselves accountable for providing excellence in student learning” (C. S., personal communication, 2016), Chippewa Valley Technical College respondents suggesting, "we have four core values; they guide our decision-making” (A. S., personal communication, 2016) and that "our mission, values, and culture; that is who we are, what we are about" (A. F., personal communication, 2016).

Table 2. Interview Coding Groups and Thematic Nodes with Number of Sources and References

\begin{tabular}{lcc}
\hline Coding Groups & \# of Sources & \# of References \\
\hline Q1 Processes and Systems & 6 & 84 \\
AQIP/HLC & 5 & 20 \\
QRP & 3 & 9 \\
Budgeting & 3 & 9 \\
Feedback & 5 & 9 \\
PDCA & 2 & 6 \\
WFA & 2 & 9 \\
Q2 Values and Culture & 6 & 82 \\
Mission and Vision & 3 & 7 \\
Core Values & 5 & 13 \\
Benchmarking & 3 & 3 \\
Partnerships & 2 & 7 \\
QRP & 2 & 2 \\
Student Focus & 3 & 12 \\
Q3 Usage for Performance Funding & 6 & 71 \\
Competitors & 3 & 14 \\
Measurement & 4 & 12 \\
PBF Criteria & 6 & 14 \\
PBF Targets & 3 & 7 \\
Q4 Effectiveness for Performance Funding & 6 & 16 \\
\hline
\end{tabular}


Student success indicators. Resulting from the analysis of measuring progress toward creating a studentfocused culture with student satisfaction and academic success indicators, findings indicated that student success measurement tools such as the Personal Assessment of College Environment, Student Satisfaction Inventory, Community College Student Success Engagement surveys, Integrated Postsecondary Education Data System and Wisconsin Technical College System reports, National Community College Benchmarking Project records, as well as competitor-benchmarking were all common among the colleges. The first three tools were used to collect feedback from students, while the rest compared student satisfaction results to peer institutions operating within or outside the Wisconsin Technical College System. Chippewa Valley Technical College files (2012) suggested that the college determined "student and stakeholder satisfaction relative to its competitors through Student Success Inventory and Community College Student Success Engagement surveys" (p. 13), while Milwaukee Area Technical College (2012) indicated, "students have the opportunity to provide feedback throughout all stages of the educational lifecycle through the Noel Levitz Student Success Inventory, Community College Student Success Engagement surveys, the Wisconsin Technical College System Graduate Follow-up surveys, and other indicators” (pp. 14-15).

Usage of Processes, Systems, Values, and Culture. Answering the question of how the colleges used their shared characteristics in the performancebased funding environment involved analyzing the connections between the five major process and system groups and their contribution to organizational operations.

Quality. Quality processes and systems played a role in leadership, societal responsibility, customer and workforce satisfaction, and measurement, being integral to college operations. Examples included positive evaluator feedback for Western Technical College: "the organization identified the need for better information and is in the beginning stages of evaluating the requirements for improvement through an AQIP project" (Western Technical College, 2011, p. 19) and indications that Milwaukee Area Technical College (2012) engaged in the AQIP process in curriculum revisions: "the process of improving a program is an adaptation of the Plan Do Check Act cycle referred to as the Plan Teach Assess, Analyze, and Adjust” (p. 16).

Benchmarking. The study found that comparisons within the Wisconsin Technical College System, external competitors, and with established tools such as the National Community College Benchmarking Project, the Integrated Postsecondary Education Data System, and Strengths, Weaknesses, Opportunities, and Threats Analysis were pertinent. Chippewa Valley Technical College (2012), for example, administered "three college wide surveys on a three-year rotating basis for an objective examination of the college's performance" (p. 5). Milwaukee Area Technical College (2012) used "comparative data sources most of which are within the educational sector” (p. iv).

Feedback. Feedback processes and systems and its Personal Assessment of College Environment, Student Satisfaction Inventory, Community College Student Success Engagement surveys, and partnership listening process elements were used in a number of operational areas, including senior leadership, governance and societal responsibility, and others, suggesting the prevalence of these mechanics in the colleges' routines.

Societal responsibility. These processes and systems, namely campus safety, emergency preparedness, financial accountability, diversity, and equity were accounted for holistically rather than in an itemized fashion. Examples were: "Western promotes legal and ethical behavior through transparency in decision-making” (Western Technical College, 2011, p. 2-3), and "Chippewa Valley is cognizant of conserving resources and maximizing efficiencies and effectiveness" (Chippewa Valley Technical College, 2012, p. 5).

Strategic planning. Strategic processes and systems were embedded in Chippewa Valley Technical College, Western Technical College, and Milwaukee Area Technical College operations in senior leadership, strategy development and implementation, workforce environment and systems, and governance outcomes activities.

Effectiveness of Processes, Systems, Values, and Culture. The effectiveness of processes, systems, values, and culture in meeting performance-based funding targets was assessed based on interviewee insight relative to whether the previously identified shared organizational features were effective performance-based funding measures.

Interviewees suggested that the commonalities identified were active, but of questionable effectiveness for outcome goal attainment. Interviewees indicated that it was premature to draw conclusions on whether their colleges' processes, systems, values, and culture were effective from a performance-based funding standpoint and that the new criteria did not have a major effect on how their colleges operated. Participants felt that performance funding, a relatively recent and externally enforced state initiative, did not change the mission, goals, or operation of their institutions, being a peripheral rather than an organically ingrained initiative.

A Chippewa Valley Technical College interviewee indicated, "I don't believe that performance based funding changed our values" (A. S., personal communication, 2016) and that "I don't think that performance funding improved our overall performance; it had a bigger impact on how we measure things" (A. S., personal communication, 2016). A Milwaukee Area Technical College interviewee's feedback was similar, "as an AQIP college, performance-based funding did not overwhelm us because we already had a lot of these 
processes” (B. S., personal communication, 2016), clearly indicating the lack of internal buy-in, "performance funding criteria came externally; it's from the outside, and they don't measure things in the way we do" (B. S., personal communication, 2016).

Western Technical College respondents supported the deduction that the colleges included in the study did not feel they needed to change in response to the performance funding measures, suggesting, "if we can be a high performing college or a high performing organization, it will certainly impact the funding we receive as part of that; performance funding is all about that, high performing organizations" (C. F., personal communication, 2016), and "organizational practices are really important to how we work as an organization; I feel like if we really do all those things well, and keep our focus, we will score high in performance-based funding and we'll do well” (C. S., personal communication, 2016).

The outcomes implied that despite the changes in state funding, the traditional processes, systems, values, and culture of the three colleges examined remained in place with minor modifications relative to measurement. This meant that the processes, systems, values, and culture shared by the three colleges were not aligned with the performance-based funding criteria, and the colleges were not using them to meet performance-based funding targets.

In the opinion of a Chippewa Valley Technical College interviewee "the fact that the state chose to pay us some state aid based on this outcome-funding model doesn't really change anything” and that "we always cared about the students, about the employers, about our district; outcomes funding really has no bearing on that" (A. F., personal communication, 2016).

A participant affiliated with Western Technical Colleges stated, "As an organization, we firmly believe that if we're really focused on what our strategic goals are for the organization, the quality kinds of things, the performance pieces will follow suit” (C. S., personal communication, 2016).

The perception of a Milwaukee Area Technical College respondent was no different: "We had all these processes in place before the state came up with performance-based funding criteria" (B. S., personal communication, 2016) and "I would say that the schools that are doing well in performance-based funding are the schools that were already improvement-based schools" (B. S., personal communication, 2016).

The findings of this research suggested that the goal of performance-based funding stated as "promoting greater effectiveness and efficiency for higher education institutions, particularly when state resources are strained" (Dougherty, Natow, Bork, Jones, \& Vega, 2013) and improvement of state objectives through clarification of what the state expects from public higher education was not achieved. Chippewa Valley Technical College, Western Technical College, and Milwaukee Area Technical College institutions espoused their established processes, systems, values, and culture despite the new funding mandate tied to attainment of specific criteria.

Participants' opinion on whether their colleges' approach was effective for attaining state funding was that it was "a tough question to answer right now because we're in such infancy stage of performance-based funding” (C. F., personal communication, 2016), and that "it is too early to draw many conclusions" (A. F., personal communication, 2016). Overall, they perceived their organizations as high performing, student-focused entities that did not need to change.

A Western Technical College respondent submitted, "We know that we're focused on our strategic goals and increasing academic success of students; we know we can meet our results of course completion, which then also allows us to perform better on the key performance indicators we get from the state" (C. S., personal communication, 2016). The Chippewa Valley Technical College interviewee's responses followed suit, stating that, "Our values drive everything that we do, and the existence of performance funding doesn't change our values; our mission is still the same, and the way we carry it out is still the same” (A. F., personal communication, 2016).

\section{Discussion}

Shared Processes, Systems, Values, and Culture. The conclusion drawn relative to the first question was that Wisconsin Forward Award-recognized Chippewa Valley Technical College, Western Technical College, and Milwaukee Area Technical College shared common organizational processes, systems, values, and culture. The five shared process and system groups were quality, benchmarking, feedback, strategic planning, and societal responsibility. Each group comprised specific processes and systems outlined in the results section. The colleges also featured shared values and culture, including student focused mission and vision, values, and core competencies.

The conclusions drawn based on the Wisconsin Forward Award documents were supported by interview respondents suggesting that, despite the changes imposed by the performance-based funding legislation, traditionally embedded processes, systems, values, and culture were upheld by the institutions. In this, the Academic Quality Improvement Program endured as one of the most influential initiatives in both the Wisconsin Forward Award documents and the interview transcripts. Feedback and benchmarking processes and systems, as well as mission, values, and culture were shown to be significant college operations.

A key finding of this case study research was that quality, benchmarking, feedback, strategic planning, and societal responsibility processes and systems were common to Chippewa Valley Technical College, Western Technical College, and Milwaukee Area Technical College. Student-focused mission, vision, 
values, and competencies were also typical of the three Wisconsin Forward Award-recognized colleges investigated. While these features did not translate into increased state appropriations calculated according to performance-based funding metrics, they resulted in statewide acknowledgment for continuous improvement, positioning these organizations as high performing role models.

The researcher recommends, based on the findings of this research, that colleague technical and community colleges revisit their existing processes and valuesystems with performance-based funding goals in mind, considering their organizational identities in the context of continuous improvement practices featured by Chippewa Valley Technical College, Western Technical College, and Milwaukee Area Technical College, while also instilling better realization of state performance targets.

Additionally, it is important to note that this study suggests that state accountability and quality improvement initiatives directed at the Wisconsin Technical College System are contradictory, leading institutions in divergent directions. The more established Wisconsin Forward Award initiative relies on the nationally promulgated Malcolm Baldrige Performance Excellence quality standards, yet the technical colleges deemed high performing according to these criteria do not excel when evaluated based on the newly imposed performance-based criteria. The incongruence of the two state initiatives drives higher education toward conflicting goals, resulting in wasted organizational resources.

The researcher recommends, relying on the outcomes of this study, that the State of Wisconsin align its performance incentive programs in order to inspire unified, focused higher educational improvement efforts through its initiatives.

\section{Organizational Characteristics and} Performance-Based Funding. The conclusion relative to the second research question was that in the perception of the interviewees, the processes, systems, values, and culture of Chippewa Valley Technical College, Western Technical College, and Milwaukee Area Technical College were not aligned with meeting performancebased funding targets. Findings indicated that the colleges actively engaged their shared features in strategic and operational activities, but were not purposeful in aligning them with the performance-based funding expectations.

The Wisconsin-Forward Award-recognized organizations in this case study analysis did not embrace the state performance criteria, reducing the effectiveness of the performance-based funding initiative in aligning state and postsecondary education priorities. The three colleges examined by this study remained true to their historic mission and established procedures, without adjusting their institutional goals to the state mandated performance-based funding priorities. The strategic goals of the three Wisconsin Forward Award-recognized colleges were not aimed at achieving the outcomes outlined by policymakers, suggesting that the performance-based funding initiative had limited success in furthering state priorities.

The outcomes of this study confirm that the Wisconsin performance-based funding initiative has limited success. The purpose of the new financing model was increasing organizational effectiveness, instilling continuous improvement, and aligning the goals of Wisconsin Technical College System institutions with state priorities. The findings of this research indicate that Chippewa Valley Technical College, Western Technical College, and Milwaukee Area Technical College failed to align their goals to performance funding targets. For a performance-focused quality culture to be sustainable, "its basic principles have to be largely shared or at least accepted” (Vettori, Lueger, \& Knassmueller, 2007, p. 22).

The researcher recommends, based on the discoveries of this investigation, that policymakers invest in capacity building among the Wisconsin Technical College System institutions subjected to performancebased funding metrics in order to improve the success of the initiative. Better understanding the reasons and proven methods of changing focus and aligning higher educations' missions with state priorities will lead to increased commitment to and engagement with the new funding measures.

\section{References}

American Society for Quality. (2015). Baldrige National Quality Program: Education criteria for performance excellence. Retrieved from www.asq.org

Bass, B. M., Avolio, B. J., Jung, D. I., \& Berson, Y. (2003). Predicting unit performance by assessing transformational and transactional leadership. Journal of Applied Psychology, 88(2), 207-219. http://dx.doi.org/10.1037/0021-9010.88.2.207

Bowen, G. A. (2009). Document analysis as a qualitative research method. Qualitative Research Journal, 9(2), 27-40. http://dx.doi.org/10.3316/QRJ0902027

Blanco, C. D. (2012). Essential elements of state policy for college completion: Outcomes-based funding. Retrieved from http://publications.sreb.org

Burke, J. C. (2002). Funding public colleges and universities for performance: Popularity, problems, and prospects. Albany, NY: The Rockefeller Institute Press.

Burke, J. C., \& Modarresi, S. (2000). To keep or not to keep performance funding. The Journal of Higher Education, 71(4), 432-453. http://dx.doi.org/10.2307/2649147

Burman, E., \& Parker, I. (1993). Discourse analytic research: repertoires and readings of texts in action. London, UK: Routledge. 
Chippewa Valley Technical College. (2012). Wisconsin Forward Award application. Retrieved from www.cvtc.edu

Christal, M. E. (1998). State survey on performance measures: 1996-1997. Denver, CO: State Higher Education Executive Officers.

Corbin, J., \& Strauss, A. (2008). Basics of qualitative research: Techniques and procedures for developing grounded theory. Thousand Oaks, CA: Sage.

Creswell, J. W. (2012). Educational research: Planning, conducting, and evaluating quantitative and qualitative research (4th ed.). Boston, MA: Pearson.

Crow, S. D., \& Von Kollenburg, S. E. (2003). Handbook of accreditation (3rd ed.). Chicago, IL: Higher Learning Commission.

Dougherty, K. J., \& Natow, R. S. (2015). The politics of performance funding for higher education: Origins, discontinuations, and transformations. Baltimore, MD: Johns Hopkins University Press.

Dougherty, K. J., Natow, R. S., Bork, R. H., Jones, S. M., \& Vega, B. E. (2013). Accounting for higher education accountability: Political origins of state performance funding for higher education. Teachers College Record, 115(1), 1-50.

Duque, L. C., \& Weeks, J. R. (2010). Towards a model and methodology for assessing student learning outcomes and satisfaction. Quality Assurance in Education, 18(2), 84-105. http://dx.doi.org/10.1108/09684881011035321

Evans, J. (2014). Quality and performance excellence: Management, organization, and strategy. Mason, $\mathrm{OH}$ : South-Western.

Fraenkel, J. R., Wallen, N. E., \& Hyun, H. H. (2012). How to design and evaluate research in education (8th ed.). New York, NY: McGraw-Hill.

Griffin, C. (2002). The advantages and limitations of qualitative research in psychology and education. Retrieved from http://www.pseve.org

Hall, D. J., \& Kalk-Debry, S. (2012). Governor Scott Walker unveils agenda for Wisconsin during speech in California. Retrieved from http://host.madison.com/wsj

Hamilton, S., \& Black, K. (2001). Electronic institutional portfolios and the self-study: A dynamic combination for quality assurance. In S. E. Von Kollenburg (Ed.), A collection of papers on self-study and institutional improvement (Vol. 2) (pp. 39-45). Retrieved from http://files.eric.ed.gov

Hammer, M., \& Champy, J. (1993). Reengineering the corporation: A manifesto for business revolution. New York: Harper Collins.

Hanushek, E. A., \& Lindseth, A. A. (2009). Performance-based funding. Education Week, 28(33), 28-30.

HCM Strategists. (2011). Performance funding in Indiana: An analysis of lessons from the research and other state models. Retrieved from http://hcmstrategists.com

Heineman, D., \& Daniels, M. (2015). Complete to compete. Retrieved from www.nga.org

Higher Learning Commission. (2016). Choosing a pathway for reaffirmation of accreditation. Retrieved from www.hlccommission.org

Hillman, N., Kelchen, R., \& Goldrick-Rab, S. (2013). Recommendations for the effective and equitable implementation of performance-based funding for Wisconsin higher education. Retrieved from www.wiscape.wisc.edu

Hillman, N. W., Tandberg, D. A., \& Fryar, A. H. (2014). Evaluating the impacts of "new" performance-based funding in higher education. Educational Evaluation and Policy Analysis, 37(4), 501-519. http://dx.doi.org/10.3102/0162373714560224

Hinduan, Z., Wilson-Evered, E., Moss, S., \& Scanell, E. (2009). Leadership, work outcomes, and openness to change following an Indonesian bank merger. Asian Pacific Journal of Human Resources, 47(1), 59-75. http://dx.doi.org/10.1177/1038411108099290

Lichtman, M. (2013). Qualitative research in education: A user's guide (3rd ed.). Thousand Oaks, CA: Sage.

McCready, B. (2013). Performance-based funding in Wisconsin. Retrieved from www.wiscape.wisc.edu

Mehralizadeh, Y., \& Safaeemoghaddam, M. (2010). The applicability of quality management systems and models to higher education: A new perspective. TQM Journal, 22(2), 175-187. http://dx.doi.org/10.1108/17542731011024282

Miao, K. (2012). Performance-based funding of higher education: A detailed look at best practices in 6 states. Retrieved from www.americanprogress.org

Middaugh, M. F. (2012). Introduction to themed PHE issue on accreditation in higher education. Planning for Higher Education, 40(3), 5-7.

Milwaukee Area Technical College. (2012). Wisconsin Forward Award application. Retrieved from www.matc.edu

Moss-Kanter, R., \& Page, G. R. (2011). Baldrige 20-20: An executive's guide to the criteria for performance excellence. Retrieved from http://nist.gov/baldrige/publications

National Institute of Standards and Technology. (2015). Baldrige excellence framework for Education: A systems approach to improving your organization's performance. Retrieved from www.nist.gov/balrige

Noland, B. E., \& Davis, H. (2000). Improving student outcomes and institutional accountability through performance funding. Sacramento, CA: Association for the Study of Higher Education.

Reindl, T., \& Reyna, R. (2011). From information to action: Revamping higher education accountability systems. Retrieved from www.nga.org 
Reyes, M., \& Halcon, J. (1988). Racism in academia: Qualitative and quantitative research. Avebury, UK: Aldershot.

Ruben, B. D. (2007). Excellence in higher education: An integrated approach to assessment, planning, and improvement in colleges and universities. Washington, DC: NABUCO.

Shakir, S. (2010). Exploring differences in leadership and school characteristics among colleges with traditional versus continuous improvement accreditation. (Doctoral dissertation). Retrieved from www.proquest.com. (3441941)

Shields, C. M., \& Mohan, E. J. (2008). High quality education for all students: putting social justice at its heart. Teacher Development, 12(4), 289. http://dx.doi.org/10.1080/13664530802579843

Smith, J. (2011). A tribute to Dr. Joseph M. Juran. Quality, 50(3), 20.

Spangehl, S. D. (2004). Talking with academia about quality: The North Central Association of Colleges and Schools Academic Quality Improvement Project. In B. D. Ruben (Ed.), Pursuing excellence in higher education: Eight fundamental challenges (pp. 179-189). San Francisco, CA: Jossey-Bass.

SRI International. (2012). State's methods of funding higher education. Retrieved from https://www.sri.com/sites/default/files/brochures/re vised-sri_report_states_methods_of_funding _higher_education.pdf

Stake, R. E. (1995). Case studies. In Denzin, N. K. \& Lincoln, Y. S., Handbook of qualitative research (2nd ed.), 435-454. Thousand Oaks, CA: Sage.

Sullivan, T. A., Mackie, C., Massy, W. F., \& Sinha, E. (2012). Improving measurement of productivity in higher education. Retrieved from www.nap.edu
Vettori O., Lueger M., \& Knassmueller M. (2007). Dealing with ambivalences - Strategic options for nurturing a quality culture in teaching and learning. In Embedding Quality Culture in Higher Education. A selection of papers from the 1st European Forum for Quality Assurance (pp. 2127). Brussels: EUA.

Wergin, J. F. (2005). Higher education: Waking up to the importance of accreditation. Change, 37(3), 3541.

Western Association of Schools and Colleges. (2002). A guide to using evidence in the accreditation process: A resource to support institutions and evaluation teams. Retrieved from www.wascweb.org

Western Technical College. (2011). Wisconsin Forward Award application. Retrieved from www.wtc.edu

Williams, R. C. (2005). Higher education stakeholders' perceptions of Tennessee's current performance funding policy (Doctoral dissertation). Retrieved from www.proquest.com. (Order No. 3206711)

Wisconsin Center for Performance Excellence. (2015). The Forward Award: Award process, feedback, and recognition levels. Retrieved from www.wisquality.org

Wisconsin Technical College System. (2015). Budget update: Joint finance committee completes technical college-related budget voting. Retrieved from www.districtboards.org

Yin, R. K. (1994). Case study research: Design and method. Newberry Park, CA: Sage.

Zhang, L. (2009). A value-added estimate of higher education quality of U.S. states. Education Economics, 17(4), 469-489. http://dx.doi.org/10.1080/09645290701838079 